\title{
PRÁCTICAS DE SOCIALIZACIÓN POLÍTICA EN LA CONFLUENCIA JUVENIL SURGIENDO DEL SUR DE IBAGUÉ*
}

\section{POLITICAL SOCIALIZATION PRACTICES IN THE YOUTHFUL CONFLUENCE EMERGING OF THE SOUTH AREA OF THE CITY OF IBAGUÉ}

LINA ACOSTA-HuerFiA**

\section{Resumen}

Objetivo. La participación de los jóvenes del sur de Ibagué se genera bajo contextos de apatía y conflictos sociales. Este ejercicio académico brinda categorías como socialización, socialización política e ideologías, interpretadas a la luz de prácticas desarrolladas en el colectivo juvenil Surgiendo de la ciudad de Ibagué. Metodología. Esta investigación tiene una aproximación metodológica desde la etnografía reflexiva, valiéndose de entrevistas a profundidad,análisis de narrativas, entre otras. Resultados. La incidencia política se convierte en agente socializador al transmitir conocimientos e intercambiar saberes en escenarios comunitarios participando como sujetos de transformación social. Conclusión. Las formas de involucrarse en la política y el papel que los jóvenes desempeñan en sus colectividades contextualizan las dinámicas territoriales en el sur de Ibagué con miras a recuperar las organizaciones juveniles como un espacio para habitar la vida.

Palabras clave: socialización política, ideología, sentidos de comunidad, organizaciones juveniles.

\begin{abstract}
Objective. The participation of young people in the south area of Ibague is generated under contexts of apathy and social conflict. This academic exercise provides categories such as socialization, political socialization and ideologies, interpreted in the light of practices developed in the Emerging youthful collective of the city of Ibagué. Methodology. This research has a methodological approach from reflective ethnography using in-depth interviews and analysis of narratives among others. Results. The political impact becomes a socializing agent by transmitting knowledge and exchanging in community settings by participating as subjects of social transformation. Conclusion. The ways of getting involved in the politics and role that young people play in their communities contextualize the territorial dynamics in the south area of the city of Ibague with a view to recovering youthful organizations as a space to inhabit life.
\end{abstract}

Key words: political socialization, ideology, community meanings, youth organizations.

\footnotetext{
* Este trabajo académico responde a un ejercicio investigativo y comunitario con los jóvenes del sur de Ibagué por el cual obtuve el título como Especialista en Pedagogía y Desarrollo Humano de la Universidad Católica de Pereira- Colombia.

* Universidad del Tolima. Ibagué, Colombia. E-mail: lina.acosta@ucp.edu.co

(D) orcid.org/0000-0002-8764-1710 Google Scholar
} 
Prácticas de socialización política en la confluencia juvenil surgiendo del sur de Ibagué

\section{Introducción}

Los grupos juveniles manifiestan distintas formas de habitar escenarios públicos o privados relacionados con el actuar comunitario, la participación electoral, expresiones artístico/ culturales o espacios de reivindicación política. Los jóvenes precisan ser parte de alguna colectividad, dando sentido a las existencias o, incluso, como diría Albán (2013), las "reexistencias". Las formas de encontrarse y socializar con otros en colectividades específicas develan principios, valores y experiencias que les permiten tener pensamientos cercanos y sobre todo los convoca a actuar colectivamente.

Para efectos de este ejercicio académico se analizarán categorías como socialización, socialización política e ideologías, interpretadas a la luz de las prácticas desarrolladas por el colectivo juvenil Surgiendo de la ciudad de Ibagué desde hace dos años de la mano de la Fundación Yapawayra. Tiene como objetivo potencializar y articular procesos organizativos y creativos del Sur ${ }^{1}$, ampliando la participación e incidencia en lo público y comunitario por medio de la construcción colectiva.

La participación juvenil ha estado mediada por actuaciones, decisiones colectivas y reconocimiento de contextos en los cuales se asumen como sujetos políticos, es decir, posibles sujetos transformadores de realidades con una participación y apropiación de lo “común” (Echavarría, 2003). En el caso colombiano existen limitantes por la cultura de la inmediatez: se vive para resolver lo inmediato, lo urgente. La historicidad de Colombia, permeada constantemente por la violencia, también atañe a los jóvenes e implica ser pensada desde aspectos como el desplazamiento, los distintos conflictos vividos en zonas rurales y urbanas, las implicaciones y efectos del modelo de desarrollo en términos ambientales, que afecta de manera directa la calidad de vida de las personas y se manifiesta en condiciones de precariedad, pobreza y supervivencia en los ámbitos de vida social, económica y política de los seres humanos (Cuadrado, Saraza y Forero, 2013).

La insatisfacción frente a las realidades vividas ha generado sujetos determinados a transformar estos espacios desde las reflexiones, acciones ciudadanas, reuniones "al calor de un tinto" en alguna casa comunal, parque o cualquier otro lugar de barrio, se convierten en puntos de encuentro para pensar y reflexionar los territorios y las dificultades presentes en la cotidianidad. Esto quiere decir que consiguen tramitar y exigir derechos en lugares donde la presencia estatal no es integral. En consecuencia, "junto a la negligencia institucional del Estado emergen actuaciones de agenciamiento, transformación de la realidad social, acciones colectivas que responden o se manifiestan como oposición a situaciones adversas" (Cuadrado et al., 2013, p.155)

\footnotetext{
${ }^{1}$ Este "Sur" hace referencia a las comunas 11, 12 y 13 de la ciudad de Ibagué, la connotación de sur, más allá de aspectos geográficos es una expresión utilizada por la mayoría de los grupos juveniles para denotar espacios populares de resistencia.
} 
Tal como expresan Delgado y Arias (2008), el progresivo desplazamiento de los centros de poder, la emergencia de estructuras sociales como resultado de la globalización, la incidencia de las nuevas tecnologías de la información y la comunicación (TICs), la modernización de la estructura del Estado, además de los cambios acelerados en la producción y distintas formas de ejercicio de ciudadanía, han originado la creación de escenarios que definen y pre configuran la acción colectiva de organizaciones, movimientos sociales y grupos de interés que amplían espacios para el ejercicio de la ciudadanía y la política, lo cual requiere de sujetos comprometidos social y políticamente, movilizados por intereses colectivos que reconozcan otras formas de habitar el mundo.

Al reconocer características de sujetos sociales y políticos, surge la idea de pensar la socialización política como la manera de aprehender valores, ideas, normas y trasladarlas a un plano con más autonomía, en constante relación con las instituciones instauradas, pero con posibilidad de movilizar pensamientos y saberes previos que lleven a actuar colectivamente con una visión más crítica. Igualmente, la noción de ideología se presenta como un concepto problemático, en tanto tiene acepciones peyorativas o confusas, pero sirve como punto de inflexión para reconocer que cuentan con un sistema de ideas que llevan a emitir valoraciones sobre la vida y desde allí mediar el actuar.

Los saberes y prácticas construidas se plantean como caminos históricos y socialmente construidos que implican un sin número de significados apropiados en la dimensión personal y social de los seres humanos, estas representaciones simbólicas se visibilizan a través de procesos intersubjetivos y comunicativos, por medio de los cuales es posible entender los marcos interpretativos con los que las personas llevan a cabo prácticas políticas, religiosas y sociales desde donde interpretan la realidad social. Reconocer la pluralidad cultural de los grupos o colectivos juveniles requiere superar la noción de sujetos aislados y desarraigados y, por lo tanto, reconocer los procesos de grupos sociales y comunidades donde se gestan identidades sociales y políticas en función de contextos regionales, locales, de etnia y género.

Cabe resaltar que actuar colectivamente muestra tensiones y resistencias sociopolíticas en distintas dimensiones y niveles (individuales, familiares, sociales, comunitarios, espirituales, ambientales y psicológicos) al momento de asumirse como agente en la vida pública. Frecuentemente las organizaciones, colectivos, 'parches' ${ }^{2}$, subestiman la influencia política desempeñada en los territorios, debido a la apatía, al desencanto político o a los claros intereses particulares que tienen las comunidades frente a temas políticos de sus territorios. Por ello prefieren generar trabajos sociales de forma aislada, cada uno propendiendo por intereses individuales sin la oportunidad de tejer sentidos de comunidad en ningún momento. Dicho esto, parece pertinente revisar el espacio de la confluencia juvenil del sur Surgiendo, como un

\footnotetext{
${ }^{2}$ Esta palabra es utilizada por los jóvenes para definir un grupo de personas que se encuentran y comparten actividades de interés.
} 
Prácticas de socialización política en la confluencia juvenil surgiendo del sur de Ibagué

espacio donde se gestan intereses por el sentido de lo público, la democratización de la vida y la exigencia de derechos y libertades a través de las acciones colectivas como espacios de reconocimiento, las socializaciones políticas y la reproducción de saberes que influyen en sus maneras de ver y aprehender la vida social.

Históricamente han sido los jóvenes los más interesados en generar horizontes de sentido o marcos de interpretación que ayuden a encontrar significado y le den valor a su interés por pertenecer a organizaciones artísticas, LGBTI, movimientos ambientales, sociales, políticos o religiosos, etc. Estos marcos interpretativos están permeados por aspectos cognitivos, afectivos y emocionales, que dan importancia a las acciones colectivas, las reivindicaciones, los marcos de justificación ético-políticos de sus emprendimientos y las estrategias para su agenciamiento (Delgado y Arias, 2008), es decir, que a través de la interacción, la integración, las perspectivas de mundos comunes, el reconocimiento y aceptación de otro tipo de realidades, los grupos juveniles tejen sentido de comunidad y construcción social.

En este contexto, aparecen preguntas por las prácticas de socialización, socialización política y principios ideológicos, en tanto la necesidad humana de socializar en diversos contextos recurre al lenguaje como elemento socializador primordial y permite entender los valores, normas y principios que constituyen el entramado de ideas frente a la vida. Es importante empezar por señalar el conjunto de estigmas a los cuales se enfrentan los jóvenes cuando se interesan por actividades colectivas, pues estas prácticas han estado relacionadas con pandillas, vandalismo, drogadicción y grupos armados ilegales que invisibilizan y estigmatizan todo interés de estar juntos.

En respuesta, se hace evidente la necesidad de preguntar a la confluencia juvenil Surgiendo por las prácticas de socialización, las principales motivaciones que guían la acción, cómo entienden el mundo, cómo dirimen sus inquietudes, cómo - entre ellos mismos--, resuelven dificultades cotidianas y estructurales y de qué manera, ante la ausencia de una educación crítica, generan procesos de formación con vocación para la transformación de conflictos sociales.

\section{Socialización y socialización política}

Según Berger y Luckmann (1968), el concepto de socialización puede ser entendido desde dos visiones: i) la socialización primaria, en la cual el individuo atraviesa la niñez y se hace miembro de la sociedad en donde reconoce la necesidad de las cargas afectivas para generar conexión con el niño y, ii) la socialización secundaria, que requiere de un “yo" formado con anterioridad. En otras palabras, se necesitan procesos de socialización primaria previos para entrar en un proceso posterior que lleve al individuo socializado a nuevos sectores del mundo objetivo de su sociedad, al mismo tiempo requiere la internalización de submundos institucionales que vienen acompañados de un aparato legitimador, cargado de símbolos y rituales, adquisición 
específico de roles en relación con la división de trabajo que implica entonces comportamientos de rutina en un área institucional. La socialización secundaría genera espacios de encuentro fuera de la institución familia y abre la posibilidad de socializar en espacios que permitan tejer significados, identidades, representaciones sobre las instituciones en relación social y política con los otros (ver Figura 1)

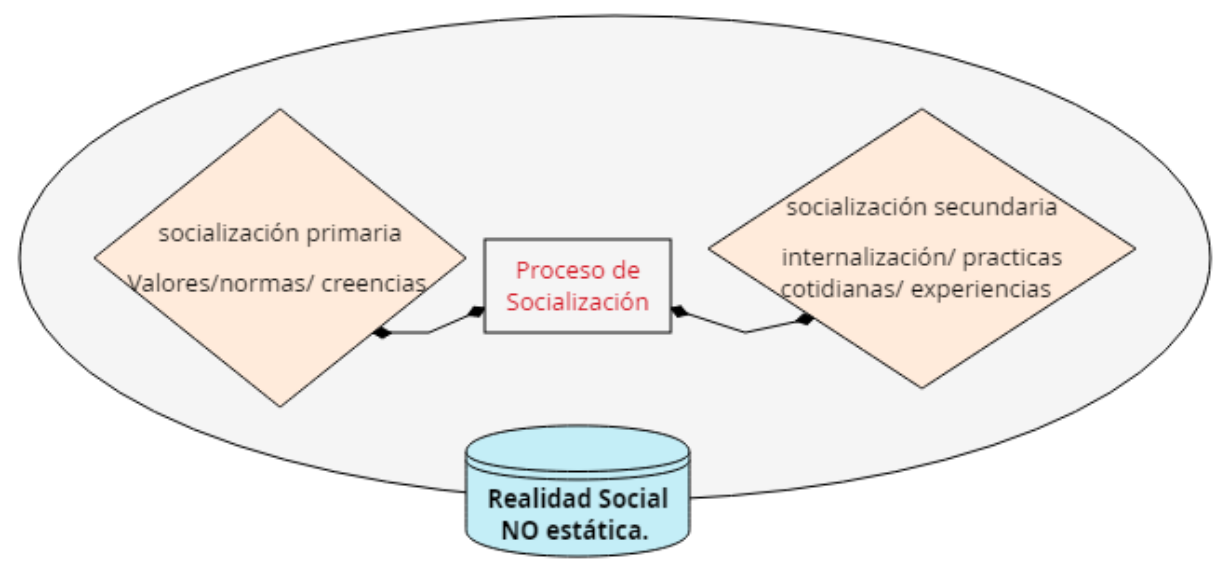

Figura 1. Procesos de socialización

Fuente: elaboración propia basada en el libro “La construcción social de la realidad”, Berger y Luckmanm, 1968.

A partir del análisis de este tipo de socialización primaria, la realidad es dada a través de lo conocido y aprehendido en el entorno familiar, pero el proceso de socialización secundaria responde a un contexto social, político, económico diferente, y es allí donde se presentan contradicciones en la manera de considerar el mundo social sin la posibilidad de transitar las distintas esferas de este.

El orden social es considerado un proceso dialéctico. Esta línea de pensamiento reconocida por Berger y Luckmann (1968) les permite proponer tres momentos que caracterizan la sociedad: i) Externalización, no entiende el ser humano dentro de una esfera social cerrada y estática, sino que continuamente las actividades humanadas se externalizan para luego convertirse en actividades habituadas o rutinas hasta ser institucionalizadas y plasmadas en la vida cotidiana. Se consideran seres humanos exteriorizados a partir de actividades que institucionalizan, es decir, se instalan en la realidad para luego percibir el mundo institucional como realidad objetiva e internalizar o considerar como suya dicha realidad. ii) Objetivación, responde a procesos por los cuales los productos externalizados de los seres humanos se consideran como objetivos y, iii) Internalización, se designa a la manera como "hacemos nuestra la realidad" e implica la aprehensión o interpretación inmediata de un acontecimiento objetivo en cuanto expresa significado, o sea, en cuanto es una manifestación de los procesos subjetivos de otro. 
Prácticas de socialización política en la confluencia juvenil surgiendo del sur de Ibagué

En consecuencia, estas actividades humanas se vuelven significativas cuando hay procesos que recurren a la identificación de un mundo social específico.

La socialización puede ser vista desde dos dimensiones importantes, la personal y la social. La social enmarca los procesos de socialización primaria que lo vincula a un contexto cultural especifico que ofrece un referente de conocimientos y sentires desde el cual se estructuran de manera activa y crítica sus juicios, valores y normas para participar en su comunidad o grupo social (Echavarría, 2003). Por su parte, la dimensión personal se da a la búsqueda de autonomía haciendo referencia al diálogo constante que establecen los sujetos consigo mismos y con los otros que, siguiendo con Echavarría (2003), permite la construcción y reconstrucción de contextos culturales y sociales. Este concepto de socialización como proceso mediador en la configuración de la identidad personal y social, conlleva a defender y reconocer la presencia activa del individuo en el marco de la configuración del tejido social que va a ser escenario, medio, condición y oportunidad de su pleno desarrollo.

\section{Socialización política}

El punto de inflexión al momento de hablar de socialización política es considerar que cuenta con un conjunto de procesos que enmarcan dicha socialización. Incluyen la internalización, objetivación, institucionalización o legitimación de un orden social desde el cual se tramitan y representan los intereses colectivos e individuales.

La socialización política puede ser entendida como el medio por el cual el sujeto hace parte y participa en la creación de constructos sociales, culturales y políticos de una comunidad, grupo de pertenencia, "parche” u organización social y política, la cual realiza prácticas de vida y al tiempo configura un proceso de desarrollo de identidad, reconocimiento y adquieren habilidades para participar en determinada sociedad. Es decir, interioriza y reconstruye conceptos, creencias, normas y valores.

La socialización política se refiere a la historia política de los individuos y las colectividades, a ese conjunto de procesos a través de los cuales se construyen y configuran los aspectos directamente relacionados con la manera de organizar y participar de asuntos públicos (Castillo y Sanchez, 2003). Estas dinámicas de socialización se adelantan "a través de la experiencia que encierra la interacción social, donde se gesta el proceso de socialización y por lo tanto de internalización del acervo cultural de conocimiento simbólicamente estructurado histórica y colectivamente por una comunidad o grupo" (Beriain, 1990, p. 89), a su vez, determinan la formación del sujeto político en singular, en una diversidad de escenarios desde los cuales se definen representaciones, conocimientos y actuaciones en lo público.

La socialización política, según Peschard (2016), se encuentra con cuestionamientos sobre el cómo, qué y cuándo las personas aprenden acerca de la política, cómo tramitan los procesos de 
aprendizaje e interiorización de valores, símbolos y actitudes frente a la misma. La socialización política ayuda a tejer puentes entre las diversas orientaciones de la población hacia los procesos políticos, entendiendo la ideología como el marco de ideas y principios, la socialización es pues la manera de aprehender dichas ideologías, que se materializan en diversas prácticas políticas y socializadoras que ayudan a reforzar la cultura y las estructuras en tanto generan procesos de reconocimiento y aceptación para los ciudadanos. Si bien, una de sus finalidades es lograr que los individuos se identifiquen y estén conformes con la estructura normativa y política de una sociedad (Peschard, 2016), también reconoce papel histórico que tienen al asumirse como agentes socializadores para cambiar y reformular prácticas que pongan en tela de juicio las mismas estructuras que alguna vez fueron consideradas establecidas, estáticas, inmóviles y perpetuadas.

\section{Ideología}

El concepto de ideología contiene dos connotaciones, una particular en tanto enmarca el escepticismo sobre ideas y representaciones del adversario, otra desde una mirada totalizante al estudiar las características y composición de la total estructura del espíritu de la época. Según Mannheim (1987) la ideología ha sido pensada desde perspectivas psicológicas con características como la falta de confianza en lo dicho por el adversario, la negación de las ideas por valoración aparente, el carácter específico y la situación vital del sujeto sobre las interpretaciones y opiniones.

Al principio la palabra ideología se designaba a la teoría de las ideas fundantes de un grupo de filósofos que rechazaban la metafísica y basaban su fundamento en la ciencia, antropología y psicología. El concepto moderno de la palabra surge cuando Napoleón Bonaparte advierte que este grupo de filósofos en oposición a sus ideales imperiales y ambiciones decide llamarlos ideólogos (Mannheim, 1987). A partir de allí empiezan a estudiar el concepto desde una visión que va más allá de la psicología y se convierte en un supuesto peyorativo que ya no tiene en cuenta solo las ideas erróneas del adversario, sino que requiere un análisis total de su estructura mental y sus modos de ser e interpretar la vida.

Una cosa es saber hasta qué punto las actitudes y juicios se hallan influenciados y alterados por la coexistencia de otros seres humanos y otra es saber cuáles son las implicaciones teóricas de mi modo de pensar, idénticas a las de compañeros de grupo o clase (Mannheim, 1987). Siendo todo esto así, la ideología cuenta con un valor dinámico porque los juicios se empiezan a medir con relación a las constantes experiencias y la emisión de juicios sobre la realidad.

El intento de definir el concepto de ideología viene acompañado de juicios de valor dentro de la academia y la sociedad, lo que ha generado que se enmarque en acepciones vagas, despectivas o faltas de fundamento, algo así como "nosotros tenemos la verdad, ellos tienen ideología”, en esa línea, la ideología en el sentido negativo fue considerada por Marx y Engels 
Prácticas de socialización política en la confluencia juvenil surgiendo del sur de Ibagué

como la "consciencia falsa" es decir, la falsedad de ideas condicionadas a consecuencia del adoctrinamiento por aquellos que ostentan el poder (Van Dijk, 2005).

Otra designación vino por parte de la naturaleza "dominante" del concepto que sirve como vehículo para legitimar el abuso del poder por grupos dominantes. Para efectos de este trabajo, se retomará el concepto de Van Dijk (2005): "Una ideología es el fundamento de las representaciones sociales compartidas por un grupo social” (p.17). Por tanto, la ideología sirve como elemento legitimador y se debe a la interacción entre individuos para concretar la acción en la vida de las personas.

En este largo trasegar conceptual, las preguntas sobre la crisis de sentido que atraviesa la vida toman relevancia entendiendo que las crisis de sentido constituyen o aportan a la consciencia humana en relación con los hechos y experiencias vividas, esto se traduce en acciones guiadas. Por ello, Surgiendo se constituye como una comunidad de sentido que no cuenta con la certeza de permanecer en el tiempo; puede llegar a ser luchas, ideas o acciones etéreas pero que dotan de sentido el actuar, constituyéndose como comunidad productora de sentido frente a los procesos colectivos (Berger y Luckmann, 1996).

\section{Contexto histórico de Surgiendo}

El sur de Ibagué, divido por el rio Combeima, está conformado por las comunas 11,12 y 13 de la ciudad de Ibagué, las cuales crecieron a espaldas del centro y norte de la ciudad a lo largo del siglo $\mathrm{XX}$, de forma más específica después de los años 60. Esta área creció como la zona industrial de la ciudad donde se instalaron fábricas y bodegas privadas y estatales, para así ir transformando sus bosques y pantanos en casas dispersas que luego se constituyeron en barrios.

En el proceso de poblamiento y construcción de los barrios del sur de Ibagué, la juventud de mediados del siglo XX asumió liderazgo en la gestión del agua y acueductos comunitarios, la construcción y pavimentación de vías, la consecución de rutas de transporte y la lucha por la materialización de derechos como la educación y la salud.

Hoy en día las y los jóvenes del sur de Ibagué cumplen un papel importante por medio de sus organizaciones e iniciativas como escuelas deportivas, culturales, artísticas, ambientales y políticas, formando principalmente a los niños y niñas de los barrios, brindándoles oportunidades para el uso del tiempo libre, así como opciones para proyectar su vida. Desde la confluencia juvenil del sur, Surgiendo, se proyectan a conocer más el territorio, investigar, generar información y cualificar los liderazgos y el papel de la juventud en la construcción del territorio. ${ }^{3}$

\footnotetext{
${ }^{3}$ Contexto histórico suministrado de documentos elaborados por la confluencia juvenil (2018) denominado "así viven los jóvenes en al sur de Ibagué" y "Plan de vida territorial del sur”.
} 
Surgiendo es la confluencia juvenil del Sur de Ibagué y apareció como resultado de un proyecto denominado Jóvenes creadores de iniciativas de desarrollo y paz de Ibagué; asimismo, está apoyada y financiada por la fundación Yapawayra, la Asociación Colombia Euskadi y el ayuntamiento de Vitoria-Gasteiz del País Vasco.

Surgiendo es motivo de un proceso de reflexión sobre el artículo 38 de la Constitución de 1991, en la cual se consagra y respeta el derecho a la Asociación dando apertura a la participación activa y colectiva del ciudadano, las dificultades se presentan cuando en aras de privatizar la vida misma instó a la ciudadanía a querer acceder a recursos públicos y privados por medio de concursos, convocatorias, proyectos y demás, lo que llevó a organizarse en $\mathrm{ONG}^{\prime} \mathrm{S}$, fundaciones, corporaciones, etc.

Antes de 1991 la gente se organizaba desde lo popular para dirimir las dificultades que vivían en sus barrios, llevar a cabo los micro proyectos sociales, participar políticamente o simplemente para ser la oposición pero desde la fecha, organizarse se volvió sinónimo de competencia pues buscaba que dichas organizaciones pequeñas compitieran por un contrato, dicha lógica organizativa aún sigue vigente y es por ello que Surgiendo busca generar diferentes formas de asociarse, distintas a la dinámica de "darse codo", sin solidaridad o unidad, no con el fin de contratar sino para por el hecho de seguir sirviendo a los demás (R. Valero, comunicación personal, 20 de junio de 2018)

\section{Perspectiva metodológica}

La presente investigación de carácter cualitativo se realizó desde una perspectiva metodológica de aproximación etnográfica - reflexiva y análisis de producción de narrativas producto del acompañamiento a encuentros, eventos y conciertos. Las entrevistas fueron realizadas en relación con el proceso que llevan como confluencia y sus respectivos procesos formativos.

Según Guber (2011), las investigaciones no se hacen "sobre la población” sino “con” y "a partir de” ella. El vehículo por excelencia de la reproducción social es el lenguaje y este tiene a su vez dos propiedades: indexicalidad y la reflexividad, la primera hace referencia a la capacidad comunicativa para suponer la existencia de significados comunes, orígenes de significados y saberes sociales compartidos y, la reflexividad hace referencias a las afirmaciones y descripciones sobre la realidad que la constituyen y la definen.

Este es un primer acercamiento que permite analizar las formas propias de socialización en el contexto del sur de Ibagué para ver cómo tramitan contextos y realidades con miras a ser transformados. La recolección de la información se llevó a cabo mediante entrevistas a profundidad grupales e individuales, con personas entre los 16 y 40 años aproximadamente, la mayoría mujeres; cada uno de ellos de distintos grupos juveniles a los cuales se les preguntó sobre formas de involucrarse en la política, maneras que han encontrado de estar juntos y una serie de reflexiones en torno al papel que desempeñan en sus colectividades. También se 
Prácticas de socialización política en la confluencia juvenil surgiendo del sur de Ibagué

adelantó una revisión documental sobre fuentes secundarias suministradas por la Fundación Yapawayra, acceso a registros fílmicos y fotográficos ${ }^{4}$ hechos por los jóvenes desde el 2017. La información también responde a la vivencia de las actividades realizadas por el grupo de jóvenes, donde fueron acompañados en varios eventos (cartografías sociales, recorridos al territorio, entrevistas a habitantes antiguos del sector, etc.) aunque las actividades, talleres formativos o eventos se trabajan desde el apoyo mutuo, esta confluencia tiene como elemento especial la autonomía frente a sus procesos organizativos. Para las entrevistas fueron convocadas personas de colectivos "antiguos" y "nuevos" las cuales desde sus temporalidades donaron a este proceso sus narrativas y reflexiones sobre la participación en la confluencia.

\section{Cuadro 1}

\begin{tabular}{ll}
\hline \multicolumn{1}{c}{ Iniciativa formativa } & \multicolumn{1}{c}{ Agente(s) socializador(es) } \\
\hline Formación folclórica y artística & - Recupera la cultura y el folclor en niños, niñas y madres \\
& cabeza de familia. \\
& - No se identifican con las formas tradicionales e históricas, \\
& por lo que apuestan por formas alternativas de hacer política. \\
\hline Formación artística en rap y break & - Utilizan el rap como ejercicio de expresión y demanda de \\
dance & los contextos sociales. \\
& - Se reconocen desde el rap para participar en política a fin de \\
& resignificar el papel del mismo, más allá de la marginalidad. \\
& Se recogen en pedagogía de la calle. \\
\hline Prácticas de formación deportivas & - Apuesta desde el futbol y el ultimate como escenarios de \\
& paz. \\
& - Encuentran en el deporte la salida para la utilización del \\
& tiempo libre y la apuesta por crear comunidad. \\
\hline Semilleros de liderazgo & - Formación a jóvenes y niños sobre JAC (juntas de \\
& acción comunal) instituciones (consejos juveniles, política \\
& pública de juventudes), formulación de proyectos para la \\
& autogestión. \\
& - Formación para el liderazgo y la participación política en \\
& espacios locales que buscan romper las formas tradicionales \\
de representación política.
\end{tabular}

\footnotetext{
${ }^{4}$ Las fotografías, videos y audios fueron obtenidas con previo consentimiento por parte de los jóvenes y no se realizó registro a ningún menor de edad.

${ }^{5}$ Antiguos, se refiere a personas que llevan más de un año en la confluencia y nuevos, personas que llevan entre 3 o 6 meses.
} 


\begin{tabular}{ll}
\hline \multicolumn{1}{c}{ Iniciativa formativa } & \multicolumn{1}{c}{ Agente(s) socializador(es) } \\
\hline Colectivos feministas & - Abordan temas sobre la violencia contra la mujer en \\
& escenarios públicos y privados. \\
& - Reconocen el papel de la mujer como agente transformador, \\
& con capacidad de reflexión crítica. $\quad$ - Convocan espacios \\
& de formación sobre machismos, identidades de género y \\
& reconocimiento histórico de la mujer. \\
\hline Colectivos ambientalistas & - Se preocupan por temas como acueductos comunitarios, \\
& proyectos minero-energéticos, la utilización del territorio, \\
& la apuesta por la defensa de los bienes comunes, etc. \\
\hline Formación comunicativa & - Apuestan sobre la utilización de medios digitales locales \\
& para dar voces a las distintas narrativas que enmarcan el \\
& contexto del sur. \\
\hline
\end{tabular}

Fuente: elaboración propia basada en las entrevistas, ejercicios etnográficos y en la información secundaria suministrada por la Fundación Yapawayra.

\section{Resultados}

A continuación se presentan los hallazgos más significativos en relación con los marcos interpretativos utilizados que en este caso fueron: socialización, socialización política, ideología y algunos vestigios de comunidades productoras de sentido.

Surgiendo: incidencia y disputas políticas

Dentro de la confluencia se encuentran claramente espacios de socialización secundaria que tejen identidades y representaciones alrededor de imaginarios sociales y políticos construidos colectivamente, es decir, se sienten parte de un lugar o colectivo gracias al carácter vinculante de las actividades realizadas, visibiliza las diversas voces, genera cuestionamientos y propuestas nuevas para las estructuras organizativas tradicionales, verticales y hegemónicas. Buscan tener espacios para impartir ideologías o conocimientos sobre el mundo, ello implica un proceso de aprendizaje, reconocimiento de habilidades y sobre todo incluye formar nuevos liderazgos que más adelante se ven materializados. Según Peschard (2016), este espacio de colectividad como expresión de socialización política y el permitir ser increpado o movilizado por los contextos sociales, políticos y económicos los lleva a tomar partido, es decir, asumir apuestas políticas y emprender acciones concretas. Se internalizan al vincular el ejercicio político desde actividades habituadas, prácticas cotidianas que se vuelven parte fundamental de la vida social. Es por ello que asumen el deporte y la danza como formas de consolidación y participación política.

En el proceso de socialización se reconoce la dimensión personal, por ello no prohíben la participación individual en temas políticos-electorales, pero hacen énfasis en la importancia de no vincular la organización en dichos procesos, lo cual genera pugnas dentro de la colectividad 
Prácticas de socialización política en la confluencia juvenil surgiendo del sur de Ibagué

porque finalmente son personas quienes la integran y la apuesta por la coherencia constante cuesta en tanto los avances, logros y proyecciones de la organización se pueden ver mediadas desde las dinámica político-electorales.

Parte de las dificultades de la socialización política, entendida como el acercamiento a la historia política desde lo individual y colectivo, se encuentran aquellas relacionadas con en el dialogo al momento de hablar de feminismo, género y las diferentes manifestaciones que tiene la cultura patriarcal dentro de instituciones, prácticas cotidianas, diálogos en el entorno familiar, social y de relaciones interpersonales. Una de las apuestas más importantes es reconocerse como sujetos políticos diversos que cuentan con puntos de encuentro en las reivindicaciones feministas y, a su vez, comprender los procesos de participación desde sus ideologías políticas.

Según Mannheim (1987) unas expresiones al momento de hablar de ideología tienen que ver con la desconfianza en el otro. Por ello, los estigmas, disputas personales y colectivas también entran en juego en el actuar colectivo de la confluencia en tanto históricamente se han alimentado desconfianzas frente a otras instituciones y frente a la representación institucional, lo que ha llevado a radicalizar los discursos de algunos colectivos frente al trabajo realizado con instituciones y, por supuesto, ayuda a deslegitimar el actuar de las organizaciones en disputa.

La radicalización afecta la cadena de afectos y se materializan en disputas por el poder, consolidación de grupos cerrados frente a temas de convocatorias y estímulos, pugnas territoriales, de población, prácticas formativas, etc. Por lo tanto, se convierten en discusiones heredadas a futuras generaciones.

La incidencia política sirve como agente socializador al transmitir conocimientos e intercambiar saberes en los espacios comunitarios para así asumir los espacios políticos como posibles sujetos de transformación (juntas de acción comunal JAC, consejos juveniles, consejos comunitarios, plataformas juveniles), lo que implica aceptar responsabilidades concretas para poder materializar las apuestas y deseos de los jóvenes en las políticas públicas locales. Si bien fenómenos como la corrupción, la limitación en el acceso institucional y la utilización de la población juvenil en épocas electorales ha llevado a algunos colectivos a negarse la posibilidad de trabajar con administraciones locales, también existen las organizaciones con posturas menos radicales que están dispuestas a trabajar de la mano de los entes estatales. Incluso otros grupos juveniles asumen su rol como mediadores entre la sociedad y el Estado, en tanto las acciones realizadas suplen el papel del Estado en lugares donde la presencia estatal no es tan fuerte; gracias a este trabajo las organizaciones juveniles ven en el Estado un aliado para generar la triada armónica: sociedad, organizaciones sociales, Estado.

La incidencia política en lo institucional o comunitario es uno de los temas que genera más discusión y disputa dentro de las organizaciones sociales porque existe el deseo de integrar sus demandas a la agenda política nacional y local, aunque desconfíen totalmente de formas de 
dialogo y tramite de demandas sociales. Una de las demandas más recurrentes apunta a dejar de considerar a los jóvenes como simples rebeldes (causantes de problemas) y mejor reconocer las acciones e ideas como apuestas distintas para los territorios. Todo esto se traduce en un proceso dialéctico en el cual aspiran a ser reconocidos como grupos con conocimientos sobre sus demandas y realidades sociales.

Otra de las implicaciones de la incidencia política es el reemplazo de la socialización primaria tardía desde los procesos pedagógicos realizado por cada colectivo de la confluencia juvenil Surgiendo, los cuales cumplen el papel de socializar ideas desde espacios de formación para recuperar el valor de la solidaridad, empatía, preocupación por el otro, autonomía, capacidad de decisión, potencializando nuevos liderazgos.

\section{Autonomías e identidades}

Al preguntar a los jóvenes de Surgiendo por las manifestación y creencias políticas en apoyo a algún partido, movimiento político o movimiento social, muchos de ellos identifican afinidad a ideologías de izquierda o progresistas que hacen parte del mismo grupo pero saben, sin enunciarlo, que son afines con "el pensamiento de izquierda". Mientras otros y otras reconocen otro tipo de posicionamientos ideológicos, sobre todo el grupo de mujeres feministas que abogan por la arenga "ni Dios, ni marido, ni partido" reconociendo estas como instituciones hegemónicas que no propenden por la emancipación del ser.

Otras personas reconocen su andar en el camino de movimientos sociales, grupos de rock, hip hop, etc., y se refieren al tema de confiar en los otros como un elemento importante frente a las adversidades vividas hoy en día y la necesidad de denunciar y mostrar compromiso político con la vida.

Alzamos la voz contra la desigualdad social, los juicios extrajudiciales del Sur, somos madres y le damos voz a las mujeres madres del Sur. Por ello la necesidad de tener incidencia social y política. La vida se construye desde las calles, las piedras no son suficientes para derrotar el poder y el abuso militar y dije ¡tenemos que cantar! ${ }^{6}$

La socialización política se manifiesta en cada forma que reconocer para hacer política desde las universidades, barrios, comunidades, juntas de acción comunal y, a su vez, enuncian una comprometida misión de construir tejido social desde el arte y distintas prácticas, tejiendo en red y reconociendo el complejo papel de marginalidad que han tenido los jóvenes en sectores rurales y urbanos. Aprendiendo a estar juntos, por ello sus acciones van encaminadas a empoderar las juventudes desde sus procesos de formación.

\footnotetext{
${ }^{6}$ Expresión utilizada por una de las integrantes del colectivo "DulimaVive"
} 
Prácticas de socialización política en la confluencia juvenil surgiendo del sur de Ibagué

Siendo así, ven en Surgiendo una plataforma para encontrarse, cuestionar, formarse y aprender procesos que cuentan con experiencia que han hecho de la vida en comunidad un horizonte de sentido que llena sus existencias, respetan las diversidades y autonomías de grupo. El llamado es a convertir a Surgiendo en una apuesta que debería permanecer en el tiempo.

Una manera para contrarrestar las formas tradicionales de hacer política es a través de la apuesta por construir sujetos políticos que caminen fortalenciendo sus identidades. Hay diversidad de pensamientos, por ende, hay múltiples formas de hacer política, entendiendo esta como es un espacio para discernir, cuestionar e increpar los discursos que emanan desde distintos colectivos.

Teniendo en cuenta las dificultades del territorio, el sentido de comunidad brinda la posibilidad de intervenir desde habilidades y saberes colectivos. Igualmente, a través de las practicas pedagógicas emprendidas buscan maneras de insertarse en el mundo económico desde lo que saben hacer, pues según ellos "el barrio se volvió la escuela a donde siempre queremos ir", lo anterior permite adquirir liderazgos, socializar y entender o comprender las posturas y las maneras por las cuales las personas deciden actuar por su territorio.

\section{Procesos pedagógicos}

Los jóvenes que forman parte de organizaciones juveniles empiezan a caminar en el mundo de lo social porque son movilizados más allá de valores que individualizan la vida, algunos se ven atravesados por hechos injustos o violentos. Esto hace que busquen crear sentidos de comunidad, grupos, colectividades, etc., una vez en colectivo se plantean procesos de socialización y después procesos de socialización política para, finalmente, preguntarse, en colectivo, cuáles serán las acciones más pertinentes para incidir en la sociedad a partir de procesos pedagógicos.

Estar en el mundo significa necesariamente estar con el mundo y con los otros. Estar en el mundo sin hacer historia, sin ser hecho por ella, sin hacer cultura, sin "tratar" su propia presencia en el mundo, sin soñar, sin cantar, sin hacer música, sin pintar, sin cuidar de la tierra, de las aguas, sin usar las manos, sin esculpir, sin filosofar, sin puntos de vista sobe el mundo, sin hacer ciencia o teología, sin asombro ante el misterio, sin aprender, sin enseñar, sin ideas de formación, sin politizar no es posible. (Freire, 2004, p. 27)

El inacabamiento del ser sirve como base de experiencia fundante para, a partir de allí, abrirse al mundo y a los otros. Esta forma de considerarse seres inacabados, inconclusos e indeterminados lleva a pensar la pedagogía fuera del espacio normalizado como lo puede ser la 
escuela y resignificar los parques y las calles en las cuales se dan al encuentro con el otro para reconstruirse en comunidad.

\section{A modo de conclusión}

Las formas de involucrarse en la política, las contradicciones y el papel que los jóvenes desempeñan en sus colectividades son expresiones que ayudan a contextualizar las dinámicas territoriales en el sur de Ibagué con miras a recuperar las organizaciones juveniles como un espacio de proyección política para habitar la vida.

Conceptos como reconocimiento, participación política, poder, transformación y pedagogía llegan como categorías emergentes para lograr ampliar el espectro interpretativo de la confluencia juvenil que cuenta con tantas apuestas, dicotomías y esperanzas. Los caminos de participación construidos por los jóvenes del sur de Ibagué se enmarcan en diversos contextos: comunitario, barrial, universitario, artístico/cultural e institucional. También se enmarcan en contexto de apatía, desconfianza, conflictos individuales y sociales que median su vinculación con la colectividad. Las acciones colectivas emprendidas permiten comprender fenómenos socio-políticos reconociendo factores históricos que desencadenan en la progresiva desigualdad social y económica que han generado condiciones de exclusión, marginalidad de los jóvenes; el análisis de estos contextos permite comprender horizontes de sentidos que develan un conjunto de principios, valores, emociones que enmarcan las actuaciones colectivas de los jóvenes que responden a contextos nacionales y locales, las cuales se encuentran ligadas a la historia y memoria construidas por los movimientos y colectivos en sus luchas (Delgado y Arias, 2008).

Los procesos de internalización, interiorización y exteriorización cuentan con diversos aparatos socializadores que les permiten construir marcos de sentido a tal punto que se consideran parte de una comunidad fuera de lo familiar y da paso al hip hop, la danza, el deporte, etc., para mezclarse con ámbitos de la vida en los que afectan las relaciones de socialización primaria recibidos en el entorno familiar o escolar.

Los espacios de socialización secundaria tejen identidades y representaciones alrededor de imaginarios sociales y políticos construidos colectivamente, es decir, se comprometen con algunos colectivos porque sus acciones o visiones de mundo brindan la posibilidad de sentirse identificados, encontrando otras maneras de habitar el mundo. En el ámbito personal y social, estas formas de socializaciones tienen consecuencias conflictivas pero la convicción y los resultados obtenidos en términos cualitativos tienden a ser tan fuertes que asumen el rol de líderes y lideresas sociales y llegan a considerar este camino como la apuesta a futuro en términos económicos y políticos. 
Prácticas de socialización política en la confluencia juvenil surgiendo del sur de Ibagué

La socialización política como forma de aprender acerca de la política recurre a los procesos de globalización a través de redes sociales para poner en discusión temas nacionales y globales que sirven como ejemplo para las acciones emprendidas en el territorio.

Si bien la socialización política de la mano de la ideología puede servir para reafirmar estructuras hegemónicas, puede ser útil para reformular prácticas permitiendo poner en tela de juicio estas mismas estructuras normativas y políticas que alguna vez consideraron establecidas, estáticas, inmóviles y perpetuadas.

Parte de las reflexiones sobre las maneras de socialización política viene acompañada de pugnas territoriales, relaciones de poder, desconfianzas que permean el actuar de la confluencia juvenil Surgiendo, ello no implica estigmatizar los escenarios políticos e ideológicos a tal punto de no encontrar formas para estar y trabajar juntos. Otra reflexión que queda en el aire es la recuperación de la pedagogía de la calle como pedagogía de vida, la confianza en los saberes populares como forma de expresión que merece ser recuperada en los currículos escolares tradicionales, pues son pedagogías pensadas desde las habilidades, experiencias, saberes colectivos y son contrastadas empíricamente todo el tiempo.

En términos ideológicos han encontrado la manera de aprender acerca de eventos políticos, marchas y debates, han logrado tejer los saberes académicos con los saberes populares lo cual les permite discutir sobre lugares y maneras de guiar la acción, con un referente frente a realidades nacionales más crítico, apuestan sobre el futuro de la colectividad en el marco del reconocimiento, la autonomía y la construcción de tejido social.

Las crisis de sentido constituyen o aportan a la consciencia humana en relación con hechos y experiencias vividas, esto se traduce en acciones guiadas. Por ello, Surgiendo como una comunidad de sentido que no cuenta con la certeza de permanecer en el tiempo, pueden inspirar luchas, ideas o acciones etéreas que dotan de sentido el actuar, constituyendo así una como comunidad productora de sentido frente a los procesos colectivos (Berger y Luckmann, 1996). Finalmente, los retos de las organizaciones que confluyen en Surgiendo tienen que ver con la manera de asumir dinámicas sociales globales y nacionales, las cuales apuntan a desestimar población joven y juzgar sus actividades por experiencias previas y juicios de valor, que valida las opiniones colectivas, llevando así a legitimar abusos de poder, quitando la posibilidad de elaborar marcos interpretativos de vida colectivos. 


\section{Referencias}

Albán, A. (2013). Pedagogías de la re-existencia. Artistas indígenas y afrocolombianos. En C. Walsh. (Ed.), Pedagogías decoloniales. Prácticas insurgentes de resistir, (re)existir y (re)vivir (pp. 455-468). Quito, Ecuador: Abya-Yala.

Berger, P. L. y Luckmann, T. (1968). La construcción social de la realidad. Buenos aires, Argentina: Amorrortu Editores.

Berger, P. y Luckmann, T. (1996). Modernidad, Pluralismo y Crisis de Sentido. ¿Qué necesidades humanas de orientación deben ser satisfechas? Estudio Públicos, 36-43.

Beriain, J. (1990). Representaciones sociales y proyecto de modernidad. Barcelona, España: Antrhopos.

Castillo, E. y Sanchez, C. (2003). ¿Democratizar la escuela o escolarizar la democracia? Dilemas de la socialización política en la escuela colombiana . Revista Colombiana de Educación, 45.

Cuadrado, B. J., Saraza, D. C. y y Forero, J. E. (2013). El agenciamiento social en contextos de emergencia: comunidades educadoras de Altos de La Florida en el municipio de Soacha. Aletheia, 5(2), 152-169. Recuperado de https://aletheia.cinde.org.co/index. $\mathrm{php} /$ ALETHEIA/article/view/165

Delgado, R. y Arias, J. (2008). La acción colectiva de los jóvenes y la construcción de ciudadanía. Revista Argentina de Sociología, 6 (11), 273.

Echavarría, G. C. V. (2003). La escuela: un escenario de formación y socialización para la construcción de identidad moral. Revista Latinoamericana de Ciencias Sociales, Niñez y Juventud, 1 (2), 15-17.

Freire, P. (2004). Pedagogía de la Autonomía: Saberes necesarios para la práctica educativa. Sao Paulo, Brasil: Paz e Terra S. A.

Guber, R. (2011). La etnografía. Método, Campo y Reflexividad. Buenos Aires, Argentina: Siglo Veintiuno Editores.

Mannheim, K. (1987). Ideología y Utopía. Una introducción a la sociología del conocimiento. México D. F., México: Fondo de Cultura Económica.

Peschard, J. (2016). La Cultura Política Democratica. Ciudad de México, México: Instituto Nacional Electoral.

Van Dijk, T. A. (2005). Política, ideología y discurso. Quórum Académico, 16-17. 